\title{
The Effects of Endocrine and Mechanical Stimulation on Stage I Lactogenesis in Bovine Mammary Epithelial Cells ${ }^{1}$
}

\author{
C. M. Stiening, ${ }^{*}$ J. B. Hoying,† M. B. Abdallah, ${ }^{*}$ A. M. Hoying,‡ R. Pandey,§ K. Greer,\# and R. J. Collier² \\ *Department of Animal Science, University of Arizona, Tucson 85721 \\ †Biomedical Engineering, University of Arizona, Tucson 85724 \\ $¥$ Children's Research Center, Arizona Health Sciences, University of Arizona, Tucson 85724 \\ §Bioinformatics Division, University of Arizona Cancer Center, Tucson 85724 \\ \#Department of Plant Science, University of Arizona, Tucson 85721
}

\begin{abstract}
The study objective was to evaluate the effect of endocrine and mechanical (gel release) signaling on bovine mammary epithelial cell ultrastructure and gene expression. Cultures receiving only one stimulus demonstrated partially differentiated ultrastructure, which included abundant polysomes, limited rough endoplasmic reticulum, and absence of secretory products, whereas the 2 stimuli together induced a more complete lactogenic phenotype that included increased rough endoplasmic reticulum, abundant lipid droplets, and secretory vesicles containing casein micelles. The structural data indicated that although synthesis of milk components was initiated, the copious synthesis and secretion associated with stage II lactogenesis was not evident. Microarray analysis revealed that both prolactin and gel release independently regulated several genes linked to a wide array of cellular activities. In combination, they regulated fewer genes targeted to lactogenesis. Genes regulated by the combination treatment included claudin 7, multiple caseins, xanthine oxidoreductase, and several protein synthesis, packaging, and transport genes. Genes related to structural activity including keratin 15 (morphogenesis), $\alpha$-spectrin (cell shape via actin cytoskeleton), and chitinaselike protein 1 (tissue remodeling) were up-regulated by the combination treatment as was the transcription factor Kruppel-like factor 2 (KLF-2). However, Snail 2, which down-regulates and inhibits tight junction components, was repressed in response to the combination treatment. These results suggest coordination between endocrine and physical signals at the genomic level that produces a more specific and targeted transcriptional response associated with stage I lactogenesis. A molecu-
\end{abstract}

Received March 2, 2007.

Accepted October 26, 2007.

${ }^{1}$ Supported in part by USDA/IFAFS 2001-52100-11211.

${ }^{2}$ Corresponding author: rcollier@ag.arizona.edu lar pathway analysis of the differentially expressed genes revealed that genes regulating cell signaling were linked to those regulating cell structure and adhesion. Key words: bovine, mammary, functional genomics, lactogenesis

\section{INTRODUCTION}

Lactogenesis, or differentiation of mammary epithelium before parturition, is divided into secretory initiation (stage I) and activation (stage II) phases (Neville et al., 2002). The morphological and functional events that characterize these stages are regulated by numerous endocrine and autocrine/paracrine hormones and factors, as well as structural rearrangements such as tissue remodeling and changes in the extracellular matrix (Roskelley and Bissell, 1995).

Prolactin (PRL) is one of the most intensely studied hormones related to mammary gland function, where it has been implicated in mammogenesis, lactogenesis, and lactation. Systemically, PRL is a homeorhetic hormone that acts on numerous tissues in mammals activating Janns kinase/signal transducer and activator of transcription intracellular signaling pathways and coordinating many different biological responses. However, few genes regulated by PRL are common across tissues affected by prolactin (Gass et al., 2003).

An additional consideration relative to PRL in mammary epithelial cells (MEC) is the apparent crosstalk or synergistic activities observed between PRL and other lactogenic stimuli such as mechanical signaling events. Bissell et al. (1982) and Bissell and Aggeler (1987) proposed a "dynamic reciprocity" between hormonal and mechanical signals whereby hormonally stimulated changes in MEC structure induce changes in gene expression that lead to complete functional differentiation and culminate with milk synthesis and secretion (Roskelley and Bissell, 1995). Several studies have demonstrated the importance of the extracellular matrix (ECM) in general, and the 3-dimensional structure 
of that matrix in particular, on MEC function (Wozniak et al., 2003; Zoubiane et al., 2004).

Objectives of this study were to identify genes differentially expressed during bovine MEC (BMEC) differentiation and to characterize the genomic response to endocrine and mechanical signals.

\section{MATERIALS AND METHODS}

\section{Tissue Culture and Sampling}

Tissue dissociation, BMEC isolation, and preparation of type I collagen was done according to McGrath (1987) as modified by Collier et al. (2006). Briefly, mammary tissue $(\sim 100 \mathrm{~g})$ from a multiparous, pregnant (6 to 7 mo), nonlactating Holstein dairy cow was finely minced and dissociated in $0.1 \%$ collagenase (Invitrogen, Carlsbad, CA). The epithelial fraction was isolated by Percoll (Sigma, St. Louis, MO) gradient cell density centrifugation. The epithelial fraction contained clumps of alveolar and ductal structures referred to as "organoids." Isolated organoids were washed and resuspended in freezing solution [Dulbecco's modified Eagle's medium (DMEM)/F-12 medium + fetal bovine serum + dimethyl sulfoxide (Invitrogen)] and evenly aliquotted into 1.5$\mathrm{mL}$ cryovials at an estimated concentration of $1 \times 10^{7}$ organoids $/ \mathrm{mL}$. Vials were stored in liquid nitrogen until culture, at which time 1 vial per 24 -well culture plate was removed and thawed (5 to $6 \mathrm{~min}$ in a $37^{\circ} \mathrm{C}$ water bath). Organoids were transferred to a single $15-\mathrm{mL}$ tube, diluted 1:1 with DMEM/F-12, spun for 4 to $5 \mathrm{~min}$ at minimum speed (500 rpm), and resuspended in 500 $\mu \mathrm{L}$ of DMEM/F-12. The cell suspension was then ready to be added to freshly prepared and neutralized collagen solution. Stock collagen was obtained from rat-tail tendons as previously described (McGrath, 1987) and was neutralized using a mixture of $10 \times$ Hanks' balanced salt solution and $0.34 \mathrm{~N} \mathrm{NaOH} \mathrm{(10:9)} \mathrm{at} \mathrm{a} \mathrm{ratio} \mathrm{of} 2 \mathrm{~mL}$ per $8 \mathrm{~mL}$ of collagen. Before adding organoids, a base layer of $300 \mu \mathrm{L}$ of collagen per well was added to the culture plate(s) at room temperature. Resuspended organoids (suspended in $500 \mu \mathrm{L}$ of DMEM/F-12) were added to the remaining neutralized collagen solution at this time and kept on ice until the base layer gelled (3 to $5 \mathrm{~min}$ ); $500 \mu \mathrm{L} /$ well of the collagen-cell suspension was then pipetted slowly over the top of the base layer and allowed to gel for 20 to $30 \mathrm{~min}$ at room temperature or in the incubator $\left(37^{\circ} \mathrm{C}, 5 \% \mathrm{CO}_{2}\right)$. Media was then added directly to cultures at a volume of $500 \mu \mathrm{L} / \mathrm{well}$. Growth medium consisted of serum-free DMEM/F-12, $0.1 \% \mathrm{BSA}$, antibiotic-antimycotic $(100 \mathrm{U} / \mathrm{mL}$ penicillin, $100 \mu \mathrm{g} / \mathrm{mL}$ streptomycin, and $0.25 \mu \mathrm{g}$ of amphotericin B; 15240, Invitrogen). The growth factors [recombinant bovine IGF-I, $75 \mathrm{ng} / \mathrm{mL}$; Monsanto, St. Louis, MO; and recombinant human epidermal growth factor (EGF),
$25 \mathrm{ng} / \mathrm{mL}$; Invitrogen] were included to induce proliferation and ductal development. Media were exchanged every $48 \mathrm{~h}$. At d 9 the cultures were randomly switched to 1 of 4 treatments: A) IGF-I ( $100 \mathrm{ng} / \mathrm{mL})$ and hydrocortisone (HC; 10 ng/mL, H0396, Sigma, St. Louis, MO); B) IGF-I, HC, and recombinant bovine PRL (100 ng/ $\mathrm{mL}$; Monsanto); C) IGF-I, HC, and gel release (detachment of the polymerized collagen from the surface of the well); or D) IGF-I, HC, PRL, and gel release. The cultures were maintained in these treatments for $48 \mathrm{~h}$.

\section{Experimental Design}

Samples were collected at $1,6,24$, and $48 \mathrm{~h}$ for each treatment group (A, B, C, and D). Because there were 24 wells in each plate and 4 treatment groups, there were 6 available samples of each treatment. Five of these were used for RNA analysis $(0,1,16,24$, and $48 \mathrm{~h})$, and the remaining sample was used for ultrastructure analysis. The entire culture was repeated 4 times to generate biological replicates. Upon completion, samples were pooled within treatment, generating 4 biological replicates each for A, B, C, and D for microarray analysis. A biological replicate, therefore, was a pool representing each of the 4 time points $(1,6,24$, and 48 h), randomly chosen from any of the 4 cultures.

Samples were collected following the 48-h treatment period for ultrastructural analysis, and the entire gel was fixed for analysis. The embedded gels were then examined under a dissecting scope and areas rich in alveolar units were cut out. Thick sections $(8 \mu \mathrm{m})$ were cut and stained to confirm presence of alveolar epithelial cells, and $60-\mathrm{nm}$ sections were observed for ultrastructure. Structural data were based on samples collected from at least 2 of the 4 biological replicates at the 48-h time point. Ten micrographs were taken of each treatment for evaluation. Selected micrographs were then chosen to be representative of the majority phenotype for a given treatment.

\section{cDNA Libraries}

Two mammary gland cDNA libraries (1,517 clones) and 1 pituitary gland cDNA library (828 clones) were generously provided by Monsanto. Two subtracted cDNA libraries comprised the set of mammary clones. The "lactating library" (540 clones) was created by subtracting involuted tissue from lactating tissue. The "involuted library" (977 clones) was created by performing the reciprocal subtraction (involuted minus lactating tissue). A digestive tract library was also constructed in our laboratory, which contained over 1,600 sequenced and annotated expressed sequence tags (EST) representative of bovine gastrointestinal (GI) tract tissue. 


\section{Gene Amplification, Purification, and Sequencing}

Approximately 4,600 EST representing mammary, pituitary, and digestive tract tissues were amplified directly from the glycerol stock plates by standard PCR protocol (Band et al., 2002). The T7 and Sp6 primers were used to amplify insert sequences from the mammary and GI tract cDNA library clones, whereas specific forward (5'-TGCAGGTACCGGTCCGGAATTC) and reverse (5'-CGTAAGCTTGGATCCTCTAGAG) primers were used to amplify inserts from the pituitary cDNA library clones. The PCR products were purified using 96-well PCR purification plates (Millipore, Billerica, MA) and verified by gel electrophoresis. Sequences were obtained using an ABI 3730 DNA Analyzer (GMI Inc., Ramsy, MN), and sequence data were analyzed by BLAST analysis (www.ncbi.nlm.nih.gov/blast/Blast. cgi). The EST sequences and annotations browser can be found at http://amadeus.biosci.arizona.edu/bovine; for complete access to the database and all available information, contact the corresponding author.

\section{Microarray Development}

Microarray slides were fabricated at the Genomic Research Laboratory at the University of Arizona (Tucson), according to a published protocol (Schwartz et al., 2005). Briefly, microscope slides (Gold Seal, Fisher Scientific, Rockville, MD) were cleaned with $2 \mathrm{M} \mathrm{NaOH}$ in $95 \%$ ethanol, thoroughly rinsed and dried, and then coated with $2 \% 3$-amino-propyl-trimethoxysilane (Gelest Inc., Tullytown, PA). Coated slides were thoroughly rinsed and stored in a desiccator. Stock print plates (384-well) containing purified cDNA in DNase-free water (Invitrogen) diluted 1:1 with dimethyl sulfoxide were brought to room temperature before printing. Printing on the coated slides was done using a highthroughput robot printer (BioRad, Hercules, CA) fitted with 48 SMP3 split-type pins (Telechem, Sunnyvale, $\mathrm{CA}$ ), with relative humidity set at $47 \pm 3 \%$ and temperature at $27 \pm 2{ }^{\circ} \mathrm{C}$. The robot was configured to print triplicate spots of each cDNA at a center-to-center printing distance of $200 \mu \mathrm{m}$. Printed slides (126 per run) were baked at $90^{\circ} \mathrm{C}$ for $1.5 \mathrm{~h}$, and then stored in a desiccator at room temperature.

\section{Sample Preparation}

Total RNA was isolated from cell culture samples using TRIzol reagent (Invitrogen). For precipitation, only half the recommended volume of isopropanol was used, with the other half being replaced with salt solution ( $0.8 \mathrm{M}$ sodium citrate, $1.2 \mathrm{M} \mathrm{NaCl}$ ). The concentration, purity, and integrity of RNA were confirmed on the 2100 BioAnalyzer (Agilent Technologies, Palo Alto,
CA) and spectrophotometrically (SmartSpec 3000, BioRad). Approximately $2 \mu \mathrm{g}$ of total RNA (pooled for microarray study samples) was amplified using the MessageAmp II aRNA kit (Ambion, Austin, TX), and evaluated on the Agilent BioAnalyzer. Reverse transcription reactions were performed using the EndoFree RT Kit (Ambion) with a random hexamer primer mix (Integrated DNA Technologies, Coralville, IA) in the presence of $2 \mathrm{mM}$ amino allyl dUTP. Purified cDNA was labeled green or red with Molecular Probe's Alexa Fluor 555 or 647 (Invitrogen), respectively, by incubating in the dark for $1 \mathrm{~h}$ at room temperature.

\section{Hybridizations and Scanning}

Immediately after labeling, the 2 samples to be hybridized on the same slide were combined and purified using QIAquick purification columns (Qiagen, Valencia, CA). An equal volume of $2 \times$ hybridization buffer [ $8 \times$ saline sodium citrate (SSC, sodium citrate and sodium chloride), $60 \%$ formamide, $0.2 \%$ SDS] was added along with $10 \mu \mathrm{g}$ of Cot-1 DNA and $10 \mu \mathrm{g}$ of poly dA to a final volume of $122 \mu \mathrm{L}$. Hybridization was conducted at $47^{\circ} \mathrm{C}$ and the slides were subsequently washed with 2 wash solutions ( $1 \times$ SSC, $0.1 \%$ SDS; and $0.1 \times$ SSC, $0.01 \%$ SDS), using a GeneTac Hybridization Station (Genomic Solutions, Ann Arbor, MI). Slides were rinsed in $0.1 \times$ SSC and dried. To minimize photobleaching and enhance preservation, DyeSaver2 (Genisphere, Hatfield, PA) was applied to each slide and allowed to dry in the dark for a minimum of $1 \mathrm{~h}$. Slides were scanned using a whitelight/charge-coupled device-based scanner (Applied Precision, Issaquah, WA), and raw intensity values were determined using Tracker v2.2 spot finding analysis software (MolecularWare, Irvine, CA).

\section{Estimates of Variance}

Experiment I. Two mammary tissue samples (treatment and control) were used to prepare labeled target for a "dye-swap" hybridization experiment. Total RNA was used for the cDNA synthesis reactions, and each purified cDNA product was divided into 2 aliquots, one labeled green and the other red. The 2 hybridizations were performed simultaneously in adjacent hybridization chambers. The first compared the green-labeled treatment sample and the red-labeled control sample. The second hybridization used the alternately labeled samples.

Experiment II. Primary bovine mammary epithelial cells were cultured in collagen gels, and samples (2 gels per sample) were collected at d $5(120 \mathrm{~h})$ and 7 (156 h) from either of 2 independent culture plates. Each sample was subjected to an acetic acid digestion at $37^{\circ} \mathrm{C}$ to 
dissolve the gel. Cells were then collected by centrifugation, washed once with $1 \times$ PBS and stored in RNAlater (Applied Biosystems, Foster City, CA) at $-20^{\circ}$ C. Samples were subsequently thawed, and total RNA was isolated using TRIzol reagent according to the manufacturer's protocol; RNA was then amplified, reverse transcribed, and labeled for hybridization as previously described. Incomplete block (experiment I) or balanced incomplete block (experiment II) designs were analyzed using an ANOVA model, providing a global normalization of arrays. Arrays (blocks) were treated as random effects and ANOVA estimates of variance were obtained.

\section{Data Analysis and Clustering}

The microarray data analysis was based on fitting spot intensity values to a linear ANOVA model (Greer et al., 2006). A linear ANOVA model with partitioned error was then used to accommodate replications in printed spots. All data were transformed using the Linlog variance stabilization method, which utilizes a linear transformation at low intensities when additive error is dominant and a log transformation at high intensities when multiplicative error is dominant. Data were then normalized for intensity and array position (column and row) by a Lowess regression before fitting to the linear ANOVA model. Genes were clustered across treatments by standard hierarchical clustering using SAS (SAS Institute Inc., Cary, NC), with Ward's minimum variance as the metric. Significance was determined based on a $P$-value $<0.05$ for the $F$-value associated with the treatment term in the linear model used in the ANOVA. In addition, in an effort to reduce the number of genes falsely identified as differentially expressed, only genes that were measured at levels greater than 2 standard deviations of the background for at least 3 of the samples for 1 or more treatment conditions were analyzed in the ANOVA. This technique reduced the number of genes analyzed by approximately 1,000 . We understand that, by not performing some multiple comparison correction, we are overestimating the number of differentially expressed genes, and therefore focused our analyses on classes and pathways of genes, rather than individual genes. The significance of the differential expression for any individual gene should be verified with another technology such as quantitative PCR.

\section{Pathway Analysis and Visualization}

Bovine Unigene data sets from the National Center for Biotechnology Information (NCBI, http://www. ncbi.nlm.nih.gov/) were downloaded and parsed for dif- ferentially expressed bovine GenBank accession numbers. Unigene similarity information was used to identify homologous human and mouse genes for the bovine Unigenes. Perl scripts were used for retrieval, parsing, and processing of data. The homologous human gene set was searched against Pathway Miner (Pandey et al., 2004) to identify cellular pathways influenced by the 3 treatments. Pathway Miner is a web-based interactive tool, written in Perl and Java, that provides expression patterns for affected pathways from 3 different pathway resources. The tool provides multiple outputs for interpretation of pathway perturbations. The expression patterns represented on pathways are based on a fold-change color scheme. The gene association network displays genes that are collectively influencing or participating in one or more pathways. In the network, nodes represent genes and the edges represent pathways. Thickness of the edge represents number of pathways to which the 2 connecting genes belong.

\section{Real-Time PCR}

One microgram of total RNA was DNase-treated at room temperature for $15 \mathrm{~min}$ in $10-\mu \mathrm{L}$ reactions containing $0.5 \mathrm{U}$ of DNase I (amplification grade, Invitrogen). Then, EDTA was added to a final concentration of $2.5 \mathrm{mM}$ and the DNase was inactivated at $65^{\circ} \mathrm{C}$ for $15 \mathrm{~min}$. The resulting RNA was used for cDNA synthesis (20- $\mu \mathrm{L}$ reactions) using the iScript cDNA Synthesis kit (BioRad). Analysis was conducted using the iCycler IQ Real-Time PCR Detection System (BioRad). Glyceraldehyde-3-phosphate dehydrogenase was used as the internal control gene following standard curve analyses across all treatment group samples (ribosomal protein S18 and hypoxanthine phosphoribosyltransferase 1 were also evaluated). Over the time interval of this study, the GAPDH values remained constant. Resulting gene expression data were calculated using the $2^{-\Delta \Delta \mathrm{CT}}$ method (Livak and Schmittgen, 2001). Primer sequences are available upon request or at http://amadeus.biosci.arizona.edu/bovine.

\section{Fixation and Immunofluorescence}

For structural analysis by fluorescence microscopy, an entire gel was fixed within the culture plate well by adding $2 \mathrm{~mL}$ of $2 \%$ paraformaldehyde and allowing it to set for $1.5 \mathrm{~h}$ at room temperature. Two washes were then applied using $50 \mathrm{mM}$ glycine for 20 to $25 \mathrm{~min}$ per wash at room temperature. The fixed gel was submerged in $1 \times$ PBS and stored at $4^{\circ} \mathrm{C}$. Fixed samples were labeled according to a published protocol (Larson, 1988).

Briefly, samples were permeabilized by incubation in PBS containing $0.1 \%$ Triton X-100 (Invitrogen) for 10 
min, and then the samples were incubated in PBS containing Texas Red-X phalloidin (Invitrogen). The cells were subsequently visualized and captured at $100 \times$ total magnification using an Olympus IX-70 inverted epifluorescence microscope (Olympus Center Valley, PA).

\section{Electron Microscopy}

Transmission electron microscopy was conducted at the Electron Microscopy Core Facility at the University of Arizona. Samples were collected following the 48-h treatment period and fixed using $1 \%$ formaldehyde and $3 \%$ glutaraldehyde in $0.1 M$ cacodylate buffer at $\mathrm{pH}$ 7.4. Samples were postfixed in $1.0 \%$ osmium tetroxide, dehydrated in ethanol, and embedded in Epon resin (SPI Supplies, West Chester, PA). Sixty-nanometer sections were observed using a JEOL 100 CX II transmission electron microscope (Japan Electron Optical Laboratories, Tokyo, Japan).

\section{RESULTS}

\section{Ultrastructure}

Using serum-free media and a combination of hormonal and mechanical stimuli, BMEC were transitioned from primary multicellular organoids to coordinated 3-dimensional ductal networks, and then to partly differentiated epithelia that synthesize proteins and lipids (Figures 1 to 4 ). By initially supplementing the cultures with IGF-I and EGF, the cell number began to increase (as seen by fluorometric DNA quantification, data not shown), and ductal outgrowths became visible by $48 \mathrm{~h}$ of culture (Figure 1, panel A). After $8 \mathrm{~d}$ of growth and a nearly 10-fold increase in cell number, the embedded BMEC had undergone coordinated 3dimensional growth and branching morphogenesis forming extensive ductal networks (Figure 1, panels B and C). Following lactogenic stimulation, morphological differentiation was observed as BMEC organized into ductal-alveolar structures, with large, distended lumens (Figure 1, panels D and E). Before lactogenic stimulation, TEM revealed that individual cells were undifferentiated containing mostly free polysomes and individual ribosomes with little rough endoplasmic reticulum (RER), no evidence of polarity, and no evidence of secretory products (Figure 2). To assess the lactogenic influence of hormonal and mechanical stimulation, cultures were then switched to 1 of 4 experimental media (treatments A to D). Treatment A (IGF-I and HC), which served as the reference treatment, increased RER, indicating that individual ribosomes had attached to the endoplasmic reticulum and there was increased evidence of lipid droplets and vacuolation of the cytoplasm (Figure 3). When PRL was added (treatment B), there was an increase in the number of lipid droplets and secretory vesicles (not shown). Lipid droplets and SV were also evident in cultures in treatment $\mathrm{C}$ (gel release), and the collagen fibrils that anchor the epithelial cells displayed curling and coiling as the collagen gel contracted (not shown). With the combination treatment of PRL and gel release (treatment D), several phenotypic hallmarks of stage I lactogenesis were detected, including basolateral shifting of the nucleus, dramatically larger lipid droplets, and increased Golgi as well as secretory vesicles and casein micelles (Figure 4). However, copious milk synthesis and secretion were not evident and the lumen of the alveolus contained evidence of some cellular debris (Figure 4). Thus, at the structural level there was evidence that mechanical release, prolactin, and the combination of the 2 resulted in changes in cellular morphology that were consistent with initiation of stage I lactogenesis.

\section{Gene Expression}

Real-Time Analysis. Real-time PCR analysis was used to evaluate the temporal regulation of $\beta-\mathrm{CN}$ and $\alpha$-LA gene expression in response to treatments $\mathrm{C}$ and $\mathrm{D}$ (Figure 5). Relative transcript levels were determined for the time points $0,6,24$, and $48 \mathrm{~h}$. The largest increase in expression of the gene coding for $\beta$-CN occurred between 24 and $48 \mathrm{~h}$ of stimulation, and gel release alone (treatment $\mathrm{C}$ ) induced a 65 -fold increase in $\beta$-CN mRNA, compared with a 280 -fold induction in response to PRL + gel release (treatment D). A similar profile was observed for $\alpha$-LA expression, albeit of smaller magnitude. Treatment $\mathrm{C}$ stimulated a significant increase in $\alpha$-LA transcript level and appeared to activate its expression earlier than did treatment D. Collectively, these results indicate an activation of 2 major proteins involved in milk synthesis and secretion consistent with stage I lactogenesis. Furthermore, gel release alone appears to be capable of inducing a prominent lactogenic response.

Estimates of Array Variance. Following the preliminary quality control tests, the 2 experiments outlined in Materials and Methods were conducted to obtain estimates of variance and determine if the amount of variation due to the array itself was within acceptable limits. The 2 arrays from experiment I, arranged in an incomplete block design on dye and treatment, were analyzed using the "R" statistical package (www. r-project.org/). Rough estimates of array variance (confounded with dye variance) and total variance were calculated, with array variance equal to $4.1 \times 10^{-7}$, total variance equal to 0.4175 , and a mean absolute difference between treatment groups of 1.02 (natural log 


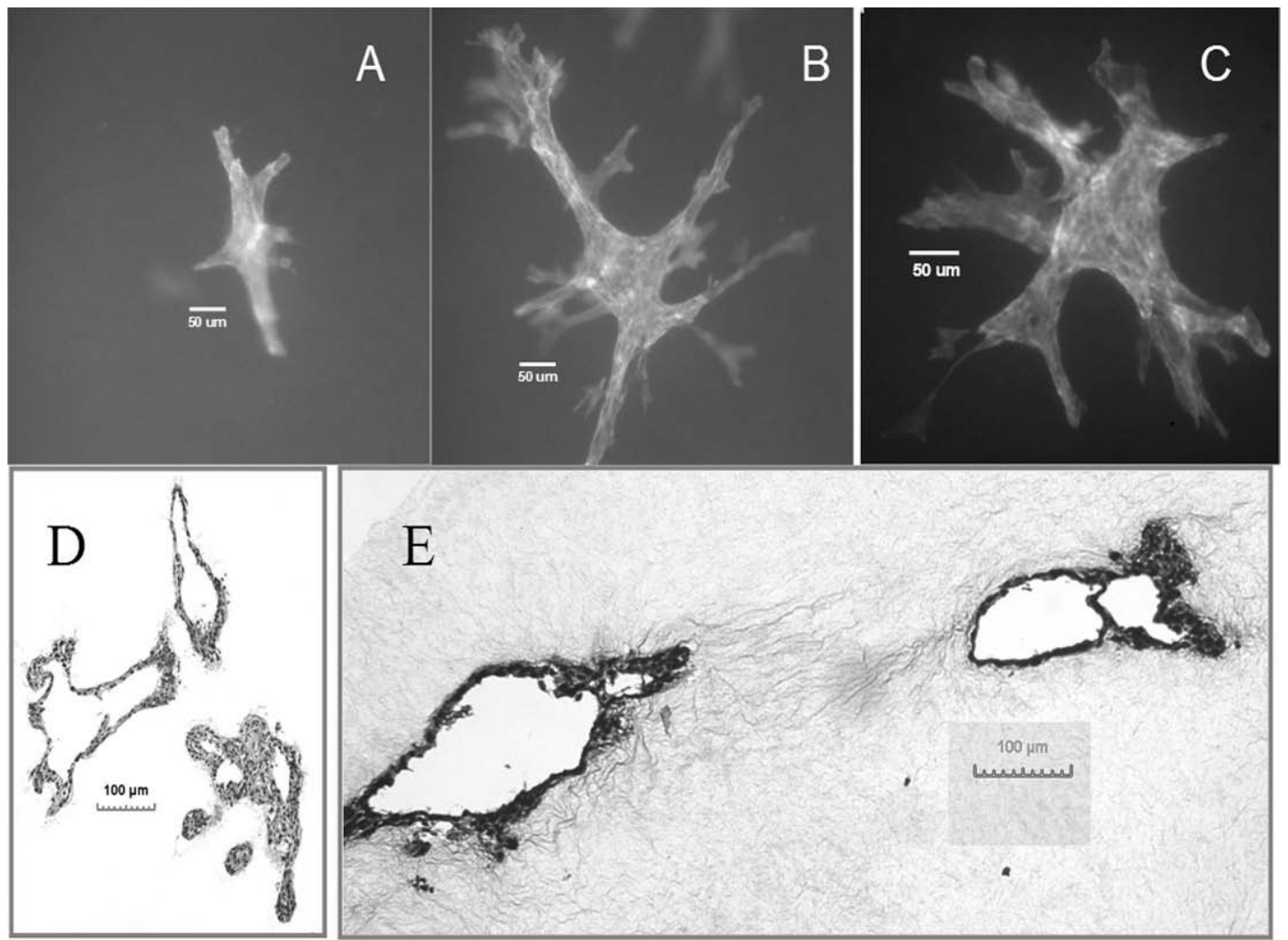

Figure 1. Phalloidin-stained bovine mammary epithelial cell cultures in collagen gels illustrating ductal branching and growth after 2 (A), 6 (B), and 10 (C) d using serum-free medium + IGF-I + epidermal growth factor (EGF); panels D and E show hemotoxylin and eosinstained $8-\mu \mathrm{m}$ sections of differentiated cultures demonstrating distended alveoli.

scale). The second experiment followed a simple loop design and was analyzed with the 3 samples arranged in a balanced incomplete block design. An estimate of the random array variance was 0.03 . In each experiment, estimates of array variance contributed to less than $11 \%$ of the total variance in expression, indicating consistent performance of the arrays.

Global Gene Expression. To better understand the genomic regulation underlying the biochemical and mechanical influences on BMEC differentiation, largescale changes in gene expression were measured using a bovine cDNA microarray according to the hybridization scheme shown in Figure 6. The statistical package CARMA (Greer et al., 2006) was used to detect significant differential expression in treatments B, C, and D relative to the expression levels in the reference treatment (A). The analysis resulted in nearly 300 sequences detected as differentially expressed. Redundancy within the array reduced the number to 259 , of which 42 were not found in the public databases and another 20 lacked functional annotation.

The number of stimulated and repressed genes, organized by treatment group, is illustrated in Figure 7 . The 27 genes within the area where all circles overlap
$(20 \uparrow, 7 \downarrow)$ were regulated similarly by all 3 treatments relative to the reference. In contrast, the 21 genes encircled only by the "Both" circle ( $5 \uparrow, 16 \downarrow)$ were exclusively regulated by treatment $\mathrm{D}$. Those genes stimulated by all 3 treatments are involved in lactation, epithelial cell differentiation, cell adhesion, protein biosynthesis and transport, morphogenesis, and cell structure and shape (Table 1). The genes regulated exclusively by treatment $\mathrm{D}$, most of which were repressed relative to treatment A, are involved in a wide range of biological processes including apoptosis, protein degradation, transcriptional repression, cell cycle regulation, mRNA processing, Wnt (wingless-related MMTV integration site protein family) signaling, tissue and cell structure, and lactation (Table 1). The few up-regulated genes in this subset were primarily involved in structural activity, such as cell shape, morphogenesis, and tissue remodeling.

To analyze functional relationships, we utilized Pathway Miner (Pandey et al., 2004), a software tool that analyzes gene expression patterns in the context of molecular pathways. Genes that were altered based on statistical significance were analyzed through Pathway Miner for pathways that were similarly or differentially 


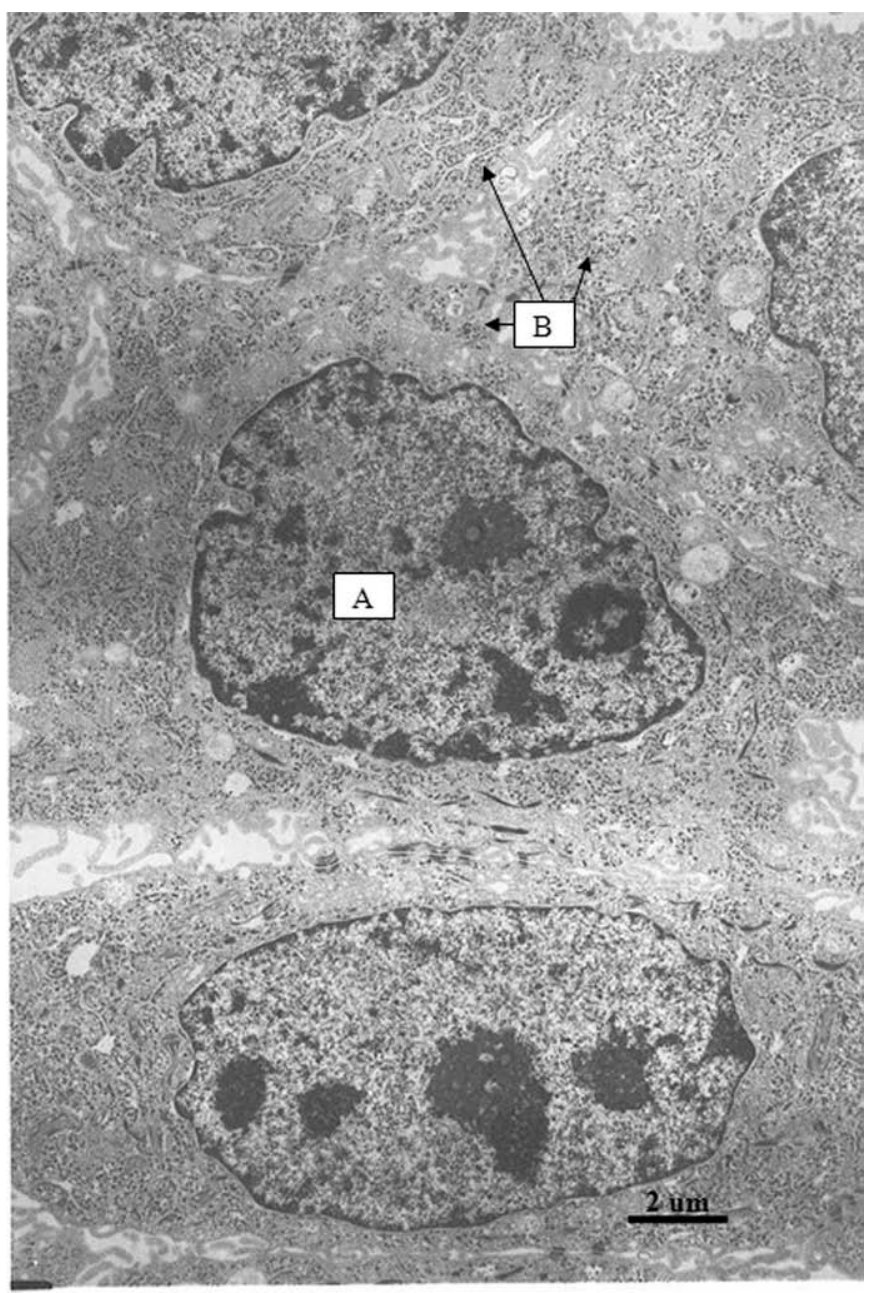

Figure 2. Electron micrograph of bovine mammary epithelial cells in cultures after $9 \mathrm{~d}$ of exposure to serum-free medium + IGF-I + epidermal growth factor. The nucleus (A) is irregular in shape and many polysomes (B) are present in the cytoplasm.

affected by treatments $\mathrm{B}, \mathrm{C}$, and $\mathrm{D}$ relative to treatment A. Table 2 lists some of the more prominent pathways identified and the relative changes in expression level. Most of the upregulated genes in response to these 3 treatments belong to adherens junction, tight junction, cytoskeleton regulation, and cell communication pathways, which contribute to changes in the structural integrity of a cell. In addition to providing a list of all functional pathways implicated within our set of differentially expressed genes, Pathway Miner also provided a network display illustrating the connections between related signaling pathways (Figure 8). The thickness of the lines connecting the genes in the pathway analysis indicates the relative importance of this pathway as a key regulatory point. Thus, calcium signaling, tight junction, and cytoskeleton regulation are playing key roles in the process of differentiation from

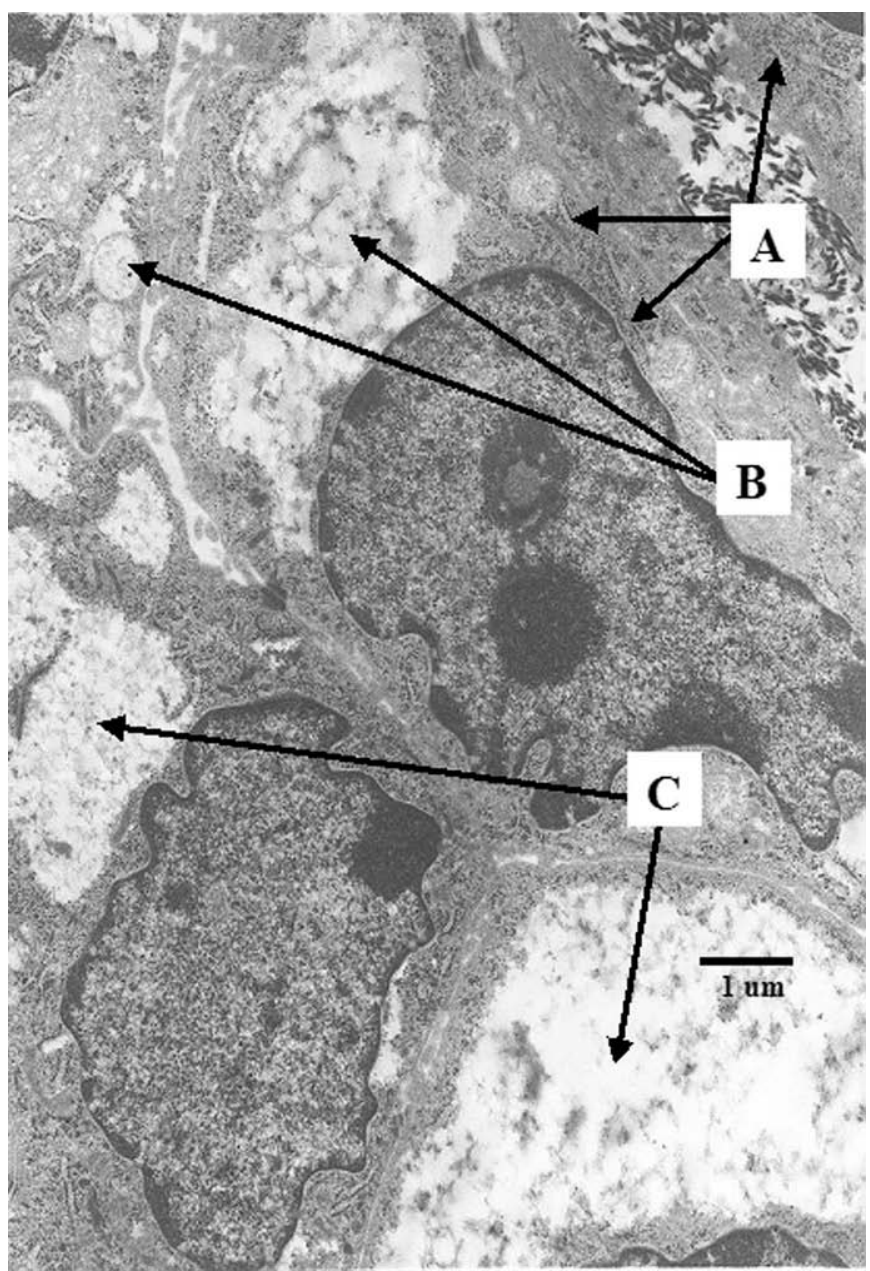

Figure 3. Ultrastructural response to $48 \mathrm{~h}$ of treatment A (IGF$\mathrm{I}+$ hydrocortisone). Note the increase in rough endoplasmic reticulum (A), appearance of secretory vesicles (B), and vacuolation of the cytoplasm (C).

growth to stage I lactogenesis. The network provides a global visualization of how a few altered genes are affecting multiple cellular pathways. Expression of several ribosomal units was also affected, which suggests influence on protein synthesis processes.

Partial validation of the microarray data was estimated by performing real-time PCR on a small subset $(n=9)$ of genes. For the comparison between real-time and microarray data, all 4 biological replicates were used to generate the real-time data, and the resulting mean was ultimately used for the comparative analysis. Figure 9 shows the mean-centered, unit-normalized expression data from the real-time vs. microarray comparison for each gene analyzed. A mean correlation of realtime and array expression data across genes was equal to $0.26 \pm 0.45(P>0.1)$. The lack of consistency in correlation across genes, particularly in the $\mathrm{B}$ and $\mathrm{D}$ treat- 


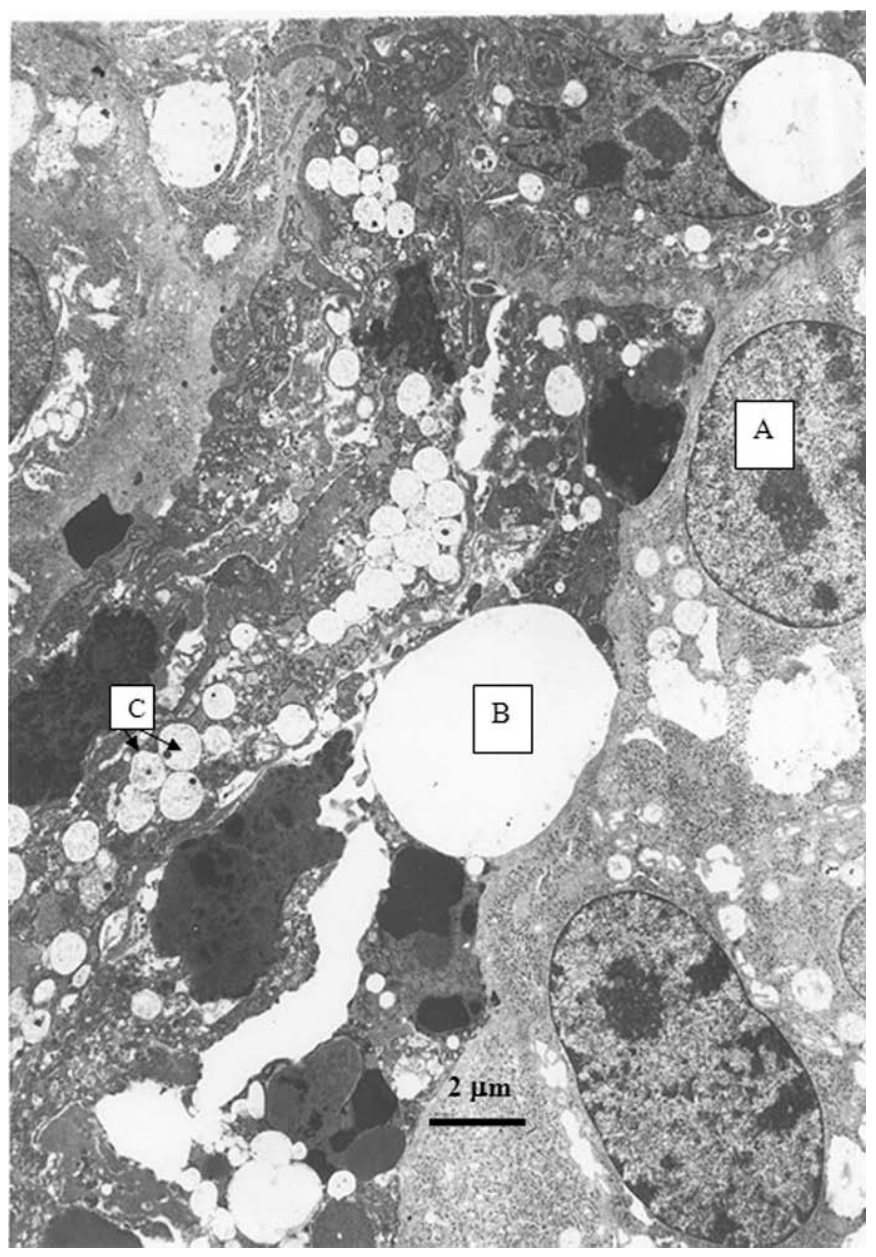

Figure 4. Ultrastructural response to the "full lactogenic complex" (treatment D, addition of PRL and gel release) shows rounding and basolateral location of the nucleus (A). In addition, the size of the lipid droplets (B) increased dramatically, as did the number of secretory vesicles $(\mathrm{C})$.

ments, was likely due to having only 2 of the 4 biological replicates represented because of sample availability in the real-time data. These differences may also have been magnified considering samples were pooled across 4 time points.

\section{DISCUSSION}

As demonstrated by McGrath (1987), primary BMEC undergo 3-dimensional growth when embedded in type I collagen gels, displaying enhanced proliferation and morphogenesis as compared with 2-dimensional cultures. In our cultures, the addition of PRL led to a partially differentiated phenotype as defined by changes in ultrastructure and gene expression. Mechanical signaling via gel release was independently lactogenic as well, promoting partial differentiation in the absence of PRL. Providing cultures with both stimuli greatly enhanced the lactogenic response. However, this response would best be characterized as the initiation of milk component synthesis (stage I lactogenesis) rather than the copious synthesis and secretion association with stage II lactogenesis. Thus, although our results indicate that PRL and gel release each possess a lactogenic capacity in BMEC, complete differentiation to stage I lactogenesis is dependent on the presence of both hormonal and mechanical signaling. Variations in cell shape have been shown to switch gene programs in cells such as those regulating growth, differentiation, and apoptosis (Ingber, 2003), and this appears to be mediated by tension-dependent changes in the actin cytoskeleton (Neville et al., 2002).

To better understand the genomic regulation underlying PRL- and ECM-dependent control of MEC differentiation, we analyzed global changes in gene expression associated with the phenotypes resulting from the treatments. Structurally, all 3 treatments promoted differentiation to some extent (Figures 2 to 4), which suggested that each treatment was likely targeting a similar subset of genes. In fact, a large proportion of the differentially expressed genes were commonly regulated by more than one treatment group, and several were similarly regulated by all 3 treatments. Because the phenotypic commonality was BMEC differentiation, we suspected that the subset affected by all 3 treatments might represent the core lactogenic genes. As illustrated in Table 1, several genes were functionally related to MEC differentiation and lactation, including claudin 7 , multiple caseins, xanthine oxidoreductase, and several protein synthesis, packaging, and transport genes. Members of the claudin gene family of tight junctional proteins are up-regulated in the mouse mammary gland during pregnancy (Blanchard et al., 2006). Xanthine oxidoreductase, traditionally considered a housekeeping gene, is critical to MEC differentiation via its role in lipid droplet formation and secretion (Vorbach et al., 2002; McManaman et al., 2004). Some of the genes identified did not make sense initially, such as vascular endothelial growth factor (VEGF) coregulated chemokine 1 (VCC1), because VEGF signaling is not known to be associated with MEC function. However, PRL has been shown to induce VEGF expression, which leads to enhanced angiogenesis in the mammary gland (Goldhar et al., 2005) and blood flow is an important determinant of milk yield during lactation (Davis and Collier, 1985); therefore, this relationship may warrant further experimentation in animal studies.

We were also intrigued by the 21 genes affected exclusively by treatment $D$ because they were the only ones associated with the fully differentiated phenotype. Spe- 

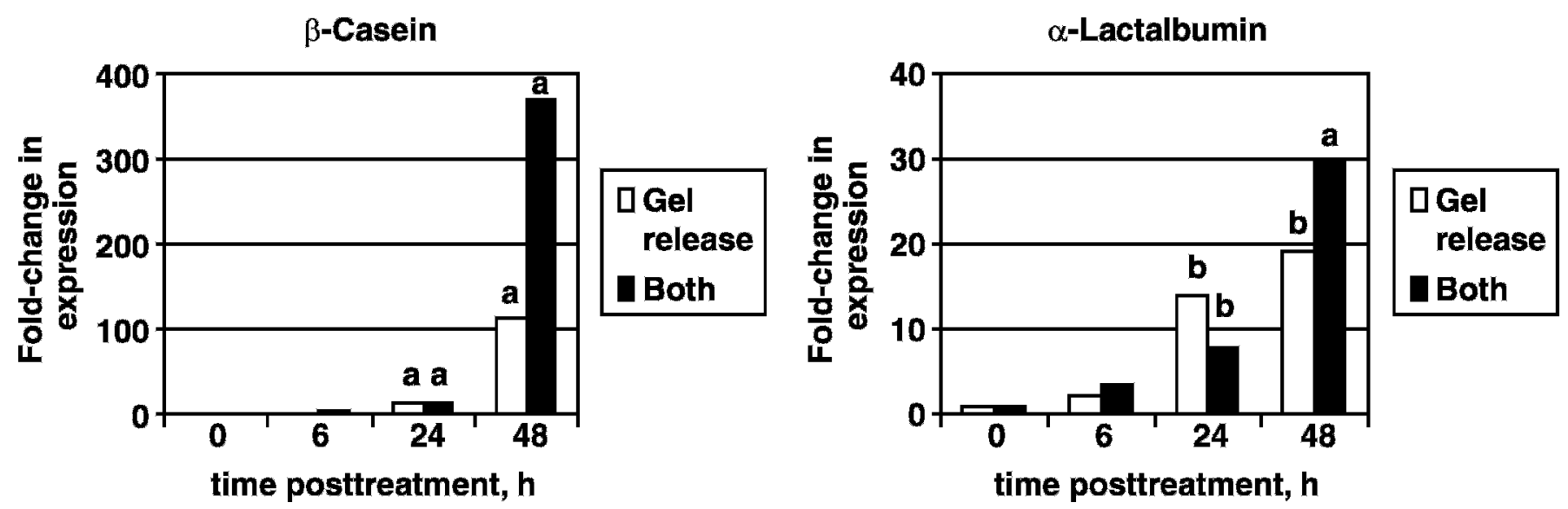

Figure 5. Changes in $\beta$-CN and $\alpha$-LA transcript level in bovine mammary epithelial cells at $0,6,24$, and $48 \mathrm{~h}$ following treatments $\mathrm{C}$ (gel release) and D (gel release + PRL). ${ }^{a} P<0.01$ and ${ }^{b} P<0.05$ for the difference in expression (as measured by real-time PCR) between pretreatment $(0 \mathrm{~h})$ and posttreatment $(6,24$, and $48 \mathrm{~h})$ samples, as determined by ANOVA and Tukey's honestly significant difference test.

cifically, expression of these genes was only altered when both endocrine and mechanical stimulation were applied. Several of these genes are related to structural activity, including keratin 15 (morphogenesis), $\alpha$-spectrin (cell shape via actin cytoskeleton), and chitinaselike protein 1 (tissue remodeling). Kruppel-like factor 2 (KLF-2), which belongs to a family of transcription factors, had a similar gene expression pattern: it was significantly repressed in treatments $\mathrm{B}$ and $\mathrm{C}$ but significantly up-regulated in treatment $\mathrm{D}$. Members of the $\mathrm{KLF}$ family are involved in regulating transcription of

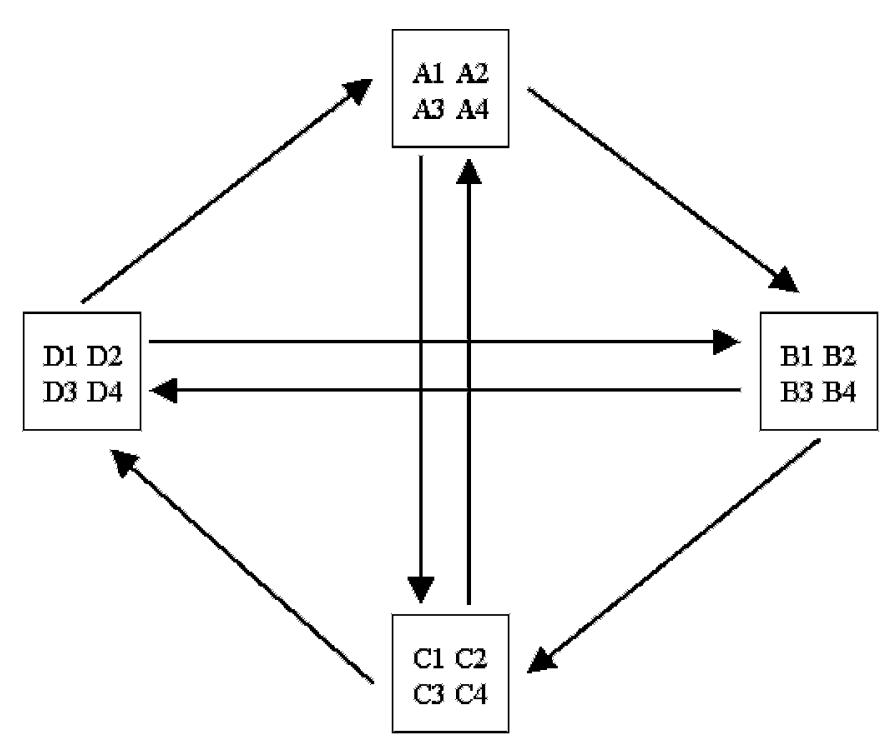

Figure 6. Hybridization scheme. The squares represent the treatment groups (A, B, C, D) and the 4 biological replicates (1, 2, 3, and 4) generated in each group (2 were labeled with green dye and 2 with red dye). Each arrow represents hybridization between 1 greenlabeled replicate and 1 red-labeled replicate. laminin, an ECM component found to stimulate $\beta$-CN expression in cultured MEC (Streuli et al., 1995). Like KLF-2, spectrin is linked to the cytoskeleton, and was reported to have a role in translocation of the nucleus

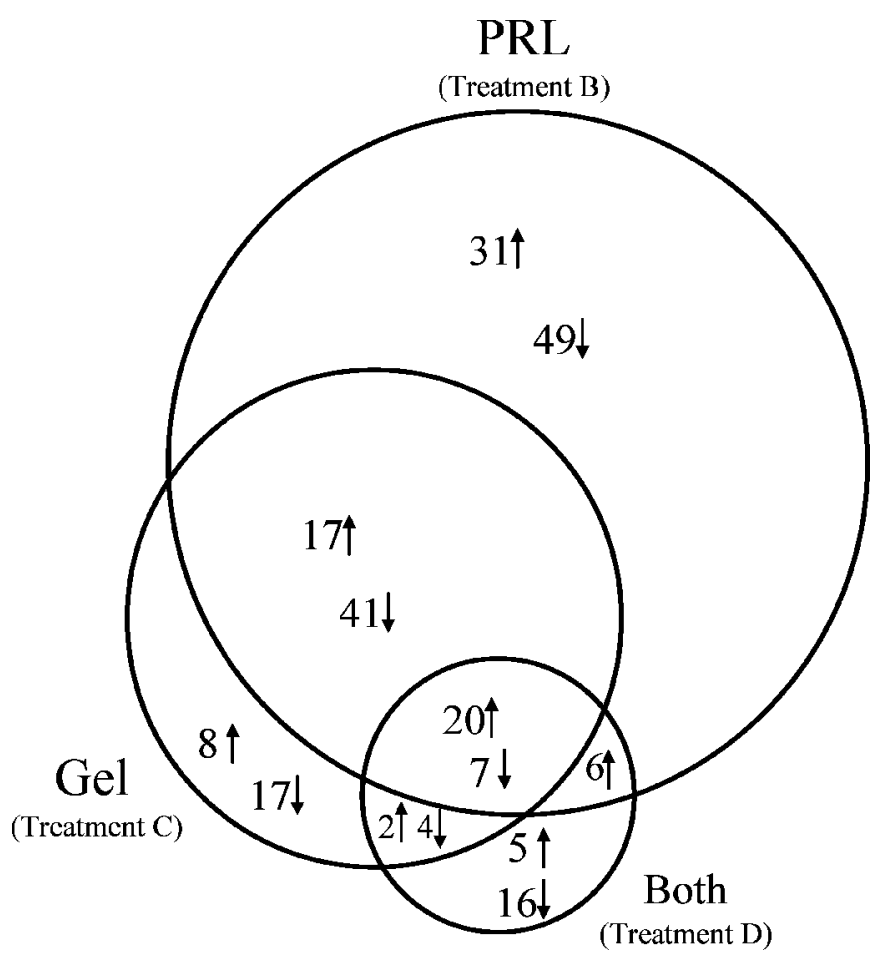

Figure 7. Venn diagram of microarray results showing the number of up- and down-regulated genes according to treatments B (prolactin, PRL), C (gel release), and D (both). Areas of overlap represent genes that were regulated similarly by more than one treatment; and area within the circle(s) corresponds to number of genes. Figure includes nonannotated genes in addition to genes listed in Table 1. 
Table 1. Genes involved in the regulation of lactogenesis, up-regulated and down-regulated genes representing the 2 groups most likely involved in regulating bovine mammary epithelial cell differentiation

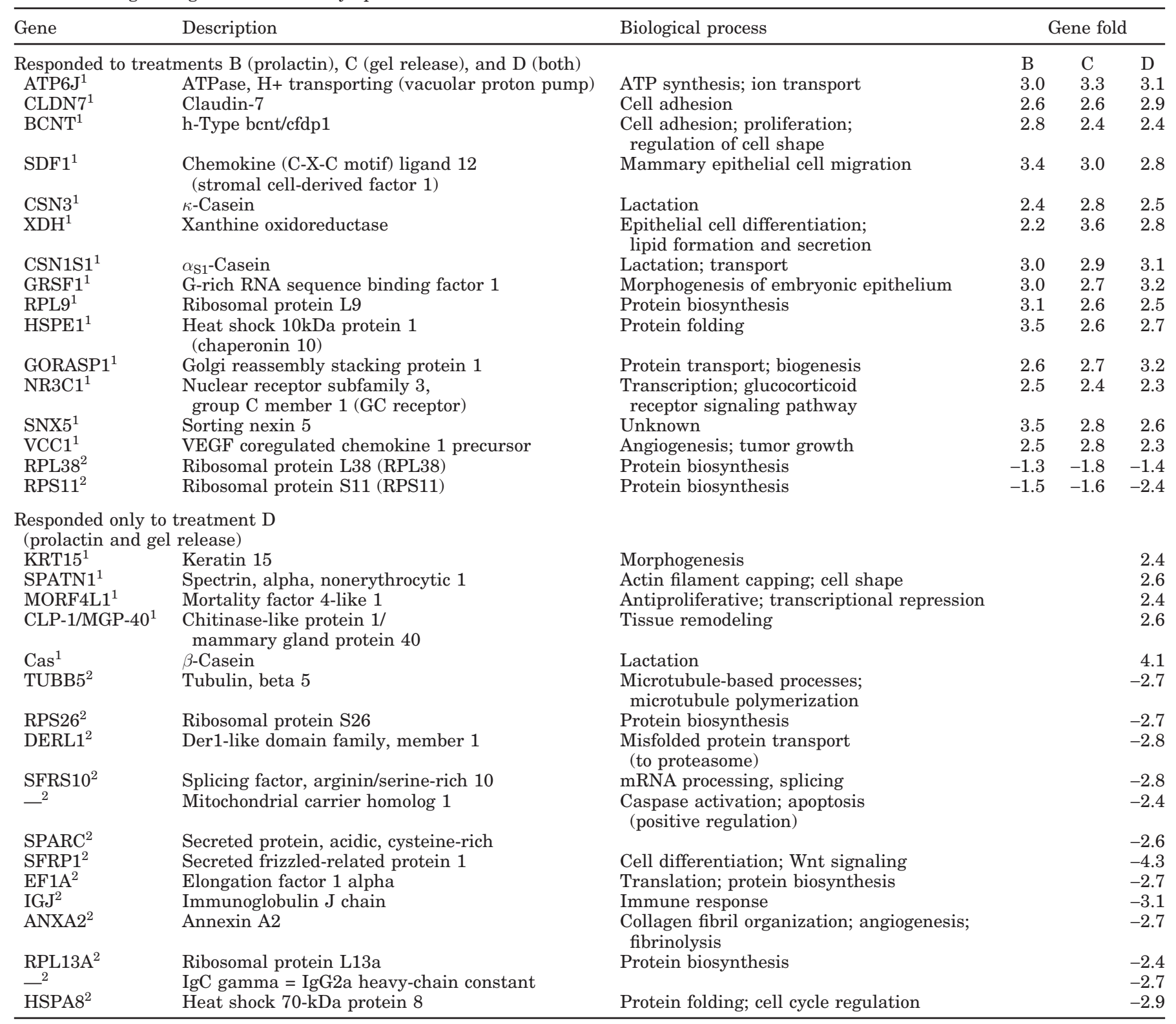

${ }^{1}$ Up-regulated genes.

${ }^{2}$ Down-regulated genes.

from medial to basal location during lactogenesis (Hofer et al., 1998).

It has also been suggested that adhesion of MEC to the ECM might regulate receptor-mediated events indirectly through the cytoskeleton as an alternative to controlling cell phenotype via enzyme pathways (Aplin and Juliano, 1999; Ingber, 2003), and that maintenance of epithelial cell differentiation is dependent on the actin cytoskeleton (Hay, 1993). Zoubiane et al. (2004) demonstrated that proximal signaling events initiated by PRL do not depend on an intact actin cytoskeleton; however, actin networks and microtubules are both necessary for continued MEC differentiation. This was confirmed by Close et al. (1997), who demonstrated that ECM components of the mammary gland provide different physical constraints on the configuration of cell surface molecules. Further, they concluded that those physical constraints are communicated to the cell interior through changes in the cytoskeleton, leading to changes in gene expression, which is consistent with Bissell's theory of dynamic reciprocity (Bissell and Aggeler, 1987). 
Table 2. Genes from the network display generated by Pathway Miner (Figure 8) are listed according to molecular pathway (except the ribosomal proteins subset)

\begin{tabular}{|c|c|c|c|c|c|}
\hline \multirow[b]{2}{*}{ Pathway name } & \multirow[b]{2}{*}{$\begin{array}{l}\text { Gene } \\
\text { name }^{1}\end{array}$} & \multirow[b]{2}{*}{$\begin{array}{c}\text { GenBank } \\
\text { accession no. }\end{array}$} & \multicolumn{3}{|c|}{ Treatment $^{3}$} \\
\hline & & & $\begin{array}{c}\text { B } \\
\text { (prolactin) }\end{array}$ & $\begin{array}{c}\mathrm{C} \\
\text { (gel release) }\end{array}$ & $\begin{array}{c}\mathrm{D} \\
(\text { prolactin }+ \text { gel release })\end{array}$ \\
\hline \multirow[t]{3}{*}{ Cell communication } & KRT9 & AB001594.1 & - & - & + \\
\hline & ACTB & AK222925.1 & ++ & + & - \\
\hline & KRT3 & AJ628418.1 & -- & + & 0 \\
\hline \multirow[t]{7}{*}{ Tight junction } & MYH9 & AB191263.1 & -- & -- & 0 \\
\hline & CTNNB1 & AB062292.1 & + & + & - \\
\hline & PPP2CA & BC000400.2 & - & -- & + \\
\hline & ACTB & AK222925.1 & ++ & + & - \\
\hline & CTNNA1 & ВC000385.2 & ++ & + & ++ \\
\hline & CLDN7 & AF093823.1 & ++ & ++ & ++ \\
\hline & SPTAN1 & $\mathrm{AB} 191262.1$ & + & - & ++ \\
\hline \multirow[t]{5}{*}{ MAPK signaling } & HSPA8 & NM_153201 & - & - & -- \\
\hline & FGFR1 & NM_023109 & ++ & +++ & ++ \\
\hline & MINK1 & NM_015716 & ++ & + & ++ \\
\hline & CASP6 & NM_032992 & + & -- & + \\
\hline & PLA2G2A & AY656695.1 & -- & -- & + \\
\hline \multirow{6}{*}{$\begin{array}{l}\text { Regulation of } \\
\text { actin cytoskeleton }\end{array}$} & MYH9 & AB191263.1 & -- & -- & 0 \\
\hline & PFN1 & BC002475.2 & + & -- & + \\
\hline & TMSB4X & BC001631.1 & -- & -- & + \\
\hline & FGFR1 & NM_023109 & ++ & +++ & ++ \\
\hline & ACTB & AK222925.1 & ++ & + & - \\
\hline & IQGAP2 & AB208856.1 & ++ & + & + \\
\hline \multirow[t]{5}{*}{ Adherens junction } & CTNNB1 & AB062292.1 & + & + & - \\
\hline & SNAI2 & AK223368.1 & + & - & -- \\
\hline & FGFR1 & NM_023109 & ++ & +++ & ++ \\
\hline & АCTB & AK222925.1 & ++ & + & - \\
\hline & CTNNA1 & BC000385.2 & ++ & + & ++ \\
\hline \multirow[t]{3}{*}{ Wnt signaling } & CTNNB1 & AB062292.1 & + & + & - \\
\hline & PPP2CA & BC000400.2 & - & -- & + \\
\hline & SFRP1 & AF001900.1 & - & - & --- \\
\hline \multirow[t]{2}{*}{ TGF- $\beta$ signaling } & $\mathrm{DCN}$ & NM_133503 & 0 & -- & -- \\
\hline & PPP2CA & BC000400.2 & - & -- & + \\
\hline
\end{tabular}

\footnotetext{
${ }^{1}$ Gene names correspond to those in the nodes in Figure 5.

${ }^{2}$ Accession number represents the human (or mouse) homolog for each gene.

${ }^{3}$ Relative changes in expression are given for each treatment, where,+- , and 0 indicate an increase, decrease, or no change in expression, respectively; the number of signs corresponds to magnitude of change relative to the reference treatment $(\mathrm{A}):---=-3.0$ downregulation; $--=-1.5$ down-regulation; $-=-1.1$ down-regulation; $0=-1.1<0<1.1$ (no change) $+=1.1$ up-regulation; $++=1.5$ up-regulation; and $+++=$ 3.0 up-regulation.
}

Results from our functional analyses were used to determine how some of the signaling pathways might be regulating MEC differentiation. A predominance of genes implicated in cell-cell communication pathways was evident, demonstrating the importance of these activities during BMEC differentiation. Using Table 2 as a guide, we compared the relative gene expression values for fully differentiated BMEC (treatment D) to the values associated with cultures receiving only one stimulus (treatments B and C). Specifically, we looked for genes that demonstrated a net change (up or down) in expression between the partly and fully differentiated phenotypes. In general, the changes in gene ex- pression suggested overall positive regulation of the pathways in Table 2.

Junctional complexes (tight, gap, adherens) play a critical role in the establishment of cell polarity in epithelia. Our results suggest an overall positive regulation of these pathways, particularly in relation to the partially differentiated phenotype. This pattern was exhibited by members of the keratin gene family. The gene encoding the tight junction protein claudin 7 (CLDN7) was elevated in all 3 lactogenic treatments suggesting its potential role as a core regulatory component in MEC differentiation. Transcription of fodrin (spectrin- $\alpha$, nonerythroid, SPTAN1), a structural pro- 


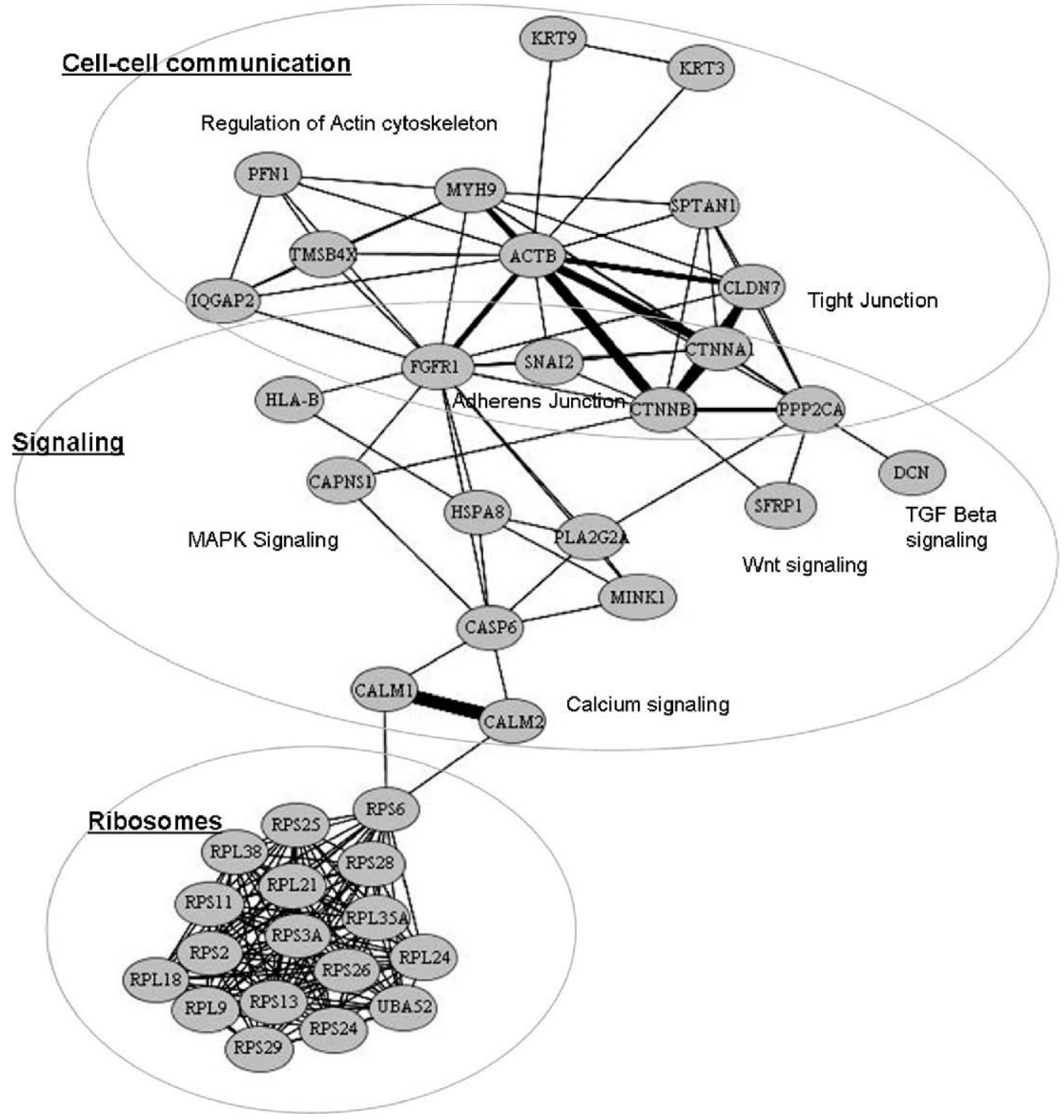

Figure 8. Differentially expressed genes from the microarray analysis as processed by Pathway Miner (Pandey et al., 2004), a software tool that analyzes functional relationships between genes. The network displayed shows the connections between related signaling pathways and the genes implicating those pathways. Nodes are labeled with the gene symbol. The thickness of the line connecting 2 genes indicates relative number of pathways in which those genes are involved. The nodes are shown in gray and do not reflect expression changes for any of the treatments. The relative changes in the expression of genes (nodes) per treatment as well as accession numbers for each gene (except the ribosomal proteins subset) can be found in Table 2 .

tein involved in cell shape and maintenance of cellular polarity (Knust, 2000), was not elevated in all treatments but was significantly upregulated in response to treatment D. Another gene of interest, SNAI2, encodes the transcription factor Snail, which down-regulates and inhibits tight junction components (Ohkubo and Ozawa, 2004). Accordingly, its expression was significantly repressed in response to treatment $\mathrm{D}$. Recent work in rat MEC suggests mitogen-activated protein kinase (MAP) kinase signaling is involved in junctional regulation (Seo et al., 2006). Members of both the classi- cal (fibroblast growth factor receptor, FGFR1; phospholipase $\mathrm{A}_{2}$, PLA2) and JNK/p38 (misshapen-like kinase, MINK1; protein phosphatase 2; PPP2CA) MAP kinase pathways were identified in this study. The PPP2CA gene encodes the protein phosphatase $2 \mathrm{~A}$ enzymes, which exist in various multisubunit forms and actively regulate tight junction (Nunbhakdi-Craig et al., 2002), TGF- $\beta$ (Griswold-Prenner et al., 1998), and Wnt (Ratcliffe et al., 2000) signaling pathways. Involvement of Wnt signaling in mammary growth and differentiation has been reported in mice (Shimizu et al., 1997). $\beta$ - 
PRL

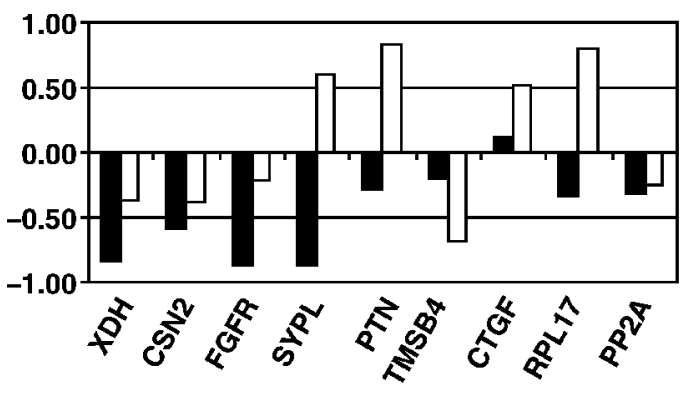

Gel release

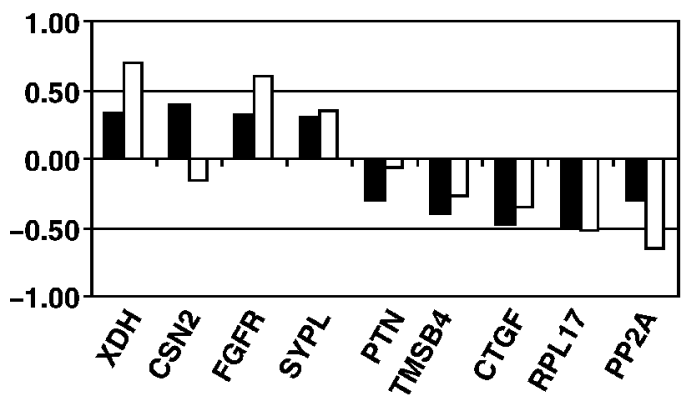

PRL + gel release

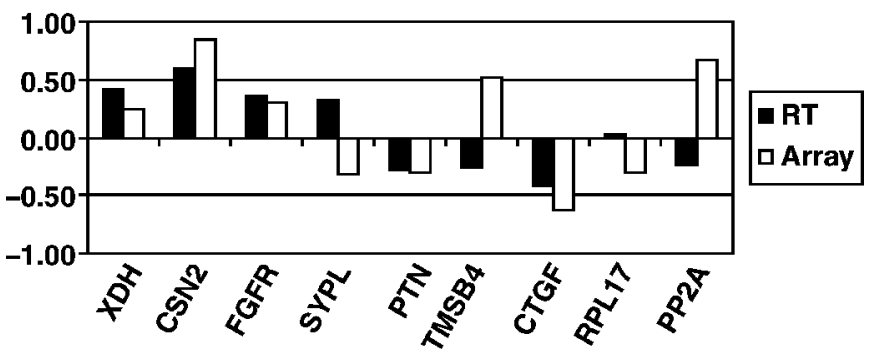

Figure 9. Comparison of expression values between microarray data and real-time PCR, separated into 3 charts corresponding to treatments B (prolactin, PRL), C (gel release), and D (PRL + gel release). The y-axis represents relative expression, with all data having been mean-centered and unit-normalized. Genes: $\mathrm{XDH}=$ xanthine oxidoreductase; CSN2 = $\beta$-casein; FGFR = fibroblast growth factor receptor; SYPL = synaptophysin-like protein; $\mathrm{PTN}=$ pleiotrophin; TMSB4 = thymosin $\beta$-4; CTGF = connective tissue growth factor; RPL17 = ribosomal protein L17; PP2A = protein phosphatase $2 \mathrm{~A}$.

Catenin, which connects multiple pathways identified in this study, plays a central role in Wnt signaling and regulation of tight junction protein gene expression (Mankertz et al., 2004). Further clarification of these networked pathways within the mammary epithelium will facilitate our understanding of the molecular mechanisms underlying mammary growth and differentiation. However, we will need to understand what factors regulate stage II lactogenesis and how they relate to changes associated with stage I lactogenesis depicted here.
Finally, as was illustrated in Figure 7, fewer genes were affected when the endocrine and mechanical stimuli were combined. This result suggests that coordination of the signals elicits an efficient and targeted genomic response, leading to a completely differentiated MEC capable of synthesizing and secreting milk. Our results parallel findings in mouse MEC studies using cell culture in which the effects of mechanical and biochemical cues on milk protein gene expression were examined (Roskelley and Bissell, 1995). These findings suggested a 2-component mechanism, the first of which involves cellular rounding and clustering. The second component was biochemical in nature, but proper translation of the signal into a functional response required cell rounding and clustering. Together, these data support the concept that endocrine and mechanical signals must act together in order for MEC to initiate stage I lactogenesis. However, Roskelley and Bissell (1995) were examining a 2-dimensional system as opposed to the 3-dimensional collagen gel culture model.

Our expression data suggest that PRL maintains a diverse and extensive regulatory capacity within BMEC, because treatment B affected transcription of more genes than any other treatment, and the genes were associated with a wide range of cellular activities and biological functions. Our results also indicate that under the appropriate lactogenic stimulation, much of this regulatory capacity is suppressed as prolactin's effects are targeted specifically at MEC differentiation.

One limitation of the current study is the exclusion of a time component, which should be a consideration for studies distinguishing between genomic regulation of the secretory initiation (stage I) and activation (stage II) phases of lactogenesis. A second limitation was the size $(4,600 \mathrm{EST})$ of the microarray. The current availability of high-quality bovine whole-genome and oligo DNA arrays will provide investigators with a greater degree of resolution in gene expression studies. Nonetheless, the data presented provide a foundation on which to design future studies.

\section{CONCLUSIONS}

Microarray analysis of BMEC exposed to lactogeneic medium and gel release indicated that these treatments independently regulated several genes linked to a diverse array of cellular activities. In combination, they regulated fewer genes, several of which were related to lactogenesis. These results suggest coordination between endocrine and physical signals at the genomic level, which produces a more specific and targeted transcriptional response. Molecular pathway analysis of the differentially expressed genes revealed that genes regu- 
lating cell signaling were linked to those regulating cell structure and adhesion

\section{REFERENCES}

Aplin, A. E., and R. L. Juliano. 1999. Integrin and cytoskeletal regulation of growth factor signaling to the MAP kinase pathway. J. Cell Sci. 112:695-706.

Band, M. R., C. Olmstead, R. E. Everts, Z. L. Liu, and H. A. Lewin. 2002. A 3800 gene microarray for cattle functional genomics: Comparison of gene expression in spleen, placenta, and brain. Anim. Biotechnol. 13:163-172.

Bissell, M. J., and J. Aggeler. 1987. Dynamic reciprocity: How do extra cellular matrix and hormones direct gene expression? Prog. Clin. Biol. Res. 249:251-262.

Bissell, M. J., H. G. Hall, and G. Parry. 1982. How does the extracellular matrix direct gene expression? J. Theor. Biol. 99:31-68.

Blanchard, A. A., P. H. Watson, R. P. Shiu, E. Leygue, A. Nistor, P. Wong, and Y. Myal. 2006. Differential expression of claudin 1, 3, and 4 during normal mammary gland development in the mouse. DNA Cell Biol. 25:79-86.

Close, M. J., A. R. Howlett, C. D. Roskelley, P. Y. Desprez, N. Bailey, B. Rowning, C. T. Teng, M. R. Stampfer, and P. Yaswen. 1997. Lactoferrin expression in mammary epithelial cells is mediated by changes in cell shape and actin cytoskeleton. J. Cell Sci. 110:2861-2871.

Collier, R. J., C. M. Stiening, B. C. Pollard, M. J. VanBaale, L. H. Baumgard, P. C. Gentry, and P. M. Coussens. 2006. Use of gene expression microarrays for evaluating environmental stress tolerance at the cellular level in cattle. J. Anim. Sci. 84(E Suppl.):E1-13.

Davis, S. R., and R. J. Collier. 1985. Mammary blood flow and regulation of substrate supply for milk synthesis. J. Dairy Sci. 68:1041-1058.

Gass, S., J. Harris, C. Ormandy, and C. Brisken. 2003. Using gene expression arrays to elucidate transcriptional profiles underlying prolactin function. J. Mammary Gland Biol. Neoplasia 8:269-285.

Goldhar, A. S., B. K. Vonderhaar, J. F. Trott, and R. C. Hovey. 2005. Prolactin-induced expression of vascular endothelial growth factor via Egr-1. Mol. Cell. Endocrinol. 232:9-19.

Greer, K. A., M. R. McReynolds, H. L. Brooks, and J. B. Hoying. 2006. CARMA: A platform for analyzing microarray datasets that incorporate replicate measures. BMC Bioinformatics 7:149.

Griswold-Prenner, I., C. Kamibayashi, E. M. Maruoka, M. C. Mumby, and R. Derynck. 1998. Physical and functional interactions between type I transforming growth factor beta receptors and Balpha, a WD-40 repeat subunit of phosphatase 2A. Mol. Cell. Biol. 18:6595-6604.

Hay, E. D. 1993. Extracellular matrix alters epithelial differentiation. Curr. Opin. Cell Biol. 5:1029-1035.

Hofer, D., T. Jons, J. Kraemer, and D. Drenckhahn. 1998. From cytoskeleton to polarity and chemoreception in the gut epithelium. Ann. N.Y. Acad. Sci. 859:75-84.

Ingber, D. E. 2003. Tensegrity II. How structural networks influence cellular information processing networks. J. Cell Sci. 116:1397-1408.

Knust, E. 2000. Control of epithelial cell shape and polarity. Curr. Opin. Genet. Dev. 10:471-475.

Larson, L. I. 1988. Immunochemical cytodetection systems. Pages 77-82 in Immunochemistry: Theory and Practice. CRC Press, Boca Raton, FL.
Livak, K. J., and T. D. Schmittgen. 2001. Analysis of relative gene expression data using real-time quantitative PCR and the 2(-delta delta C(T)) method. Methods 25:402-408.

Mankertz, J., B. Hillenbrand, S. Tavalali, O. Huber, M. Fromm, and J. D. Schulzke. 2004. Functional crosstalk between Wnt signaling and Cdx-related transcriptional activation in the regulation of the claudin-2 promoter activity. Biochem. Biophys. Res. Commun. 314:1001-1007.

McGrath, M. F. 1987. A novel system for mammary epithelial cell culture. J. Dairy Sci. 70:1967-1980.

McManaman, J. L., C. A. Palmer, S. Anderson, K. Schwertfeger, and M. C. Neville. 2004. Regulation of milk lipid formation and secretion in the mouse mammary gland. Adv. Exp. Med. Biol. 554:263-279.

Neville, M. C., T. B. McFadden, and I. Forsyth. 2002. Hormonal regulation of mammary differentiation and milk secretion. J. Mammary Gland Biol. Neoplasia 7:49-66.

Nunbhakdi-Craig, V., T. Machleidt, E. Ogris, D. Bellotto, C. L. White, III, and E. Sontag. 2002. Protein phosphatase 2A associates with and regulates atypical PKC and the epithelial tight junction complex. J. Cell Biol. 158:967-978.

Ohkubo, T., and M. Ozawa. 2004. The transcription factor Snail downregulates the tight junction components independently of E-cadherin downregulation. J. Cell Sci. 117:1675-1685.

Pandey, R., R. K. Guru, and D. W. Mount. 2004. Pathway Miner: Extracting gene association networks from molecular pathways for predicting the biological significance of gene expression microarray data. Bioinformatics 20:2156-2158.

Ratcliffe, M. J., K. Itoh, and S. Y. Sokol. 2000. A positive role for the PP2A catalytic subunit in Wnt signal transduction. J. Biol. Chem. 275:35680-35683.

Roskelley, C. D., and M. J. Bissell. 1995. Dynamic reciprocity revisited: A continuous, bi-directional flow of information between cells and the extracellular matrix regulates mammary epithelial cell function. Biochem. Cell Biol. 73:391-397.

Schwartz, M. A., A. L. Stone, K. A. Greer, J. B. Hoying, and S. K. Williams. 2005. Gene expression in tissue associated with extracellular matrix modified ePTFE. J. Biomed. Mat. Res. A 73:30-38.

Seo, M. S., J. S. Park, S. R. Yang, K. S. Park, I. S. Hong, E. H. Jo, K. S. Kang, and Y. S. Lee. 2006. Expression of MAP kinases and connexins in the differentiation of rat mammary epithelial cells. J. Vet. Med. Sci. 68:567-571.

Shimizu, H., M. A. Julius, M. Giarre, Z. Zheng, A. M. Brown, and J. Kitajewski. 1997. Transformation by Wnt family proteins correlates with regulation of beta-catenin. Cell Growth Diff. 8:13491358

Streuli, C. H., C. Schmidhauser, N. Bailey, P. Yurchenco, A. P. Skubitz, C. Roskelley, and M. J. Bissell. 1995. Laminin mediates tissuespecific gene expression in mammary epithelia. J. Cell Biol. 129:591-603.

Vorbach, C., A. Scriven, and M. R. Capecchi. 2002. The housekeeping gene xanthine oxidoreductase is necessary for milk fat droplet enveloping and secretion: Gene sharing in the lactating mammary gland. Genes Dev. 16:3223-3235.

Wozniak, M. A., R. Desai, P. A. Solski, C. J. Der, and P. J. Keely. 2003. ROCK-generated contractility regulates breast epithelial cell differentiation in response to the physical properties of a three-dimensional collagen matrix. J. Cell Biol. 163:583-595.

Zoubiane, G. S., A. Valentijn, E. T. Lowe, N. Akhtar, S. Bagley, A. P. Gilmore, and C. H. Streuli. 2004. A role for the cytoskeleton in prolactin-dependent mammary epithelial cell differentiation. J. Cell Sci. 117:271-280. 